\title{
Effect of Combination Therapy on Adherence Among US Patients Initiating Therapy for Hypertension: a Cohort Study
}

\author{
Julie C. Lauffenburger, PharmD, PhD, Joan E. Landon, MPH, and Michael A. Fischer, MD, MS \\ Division of Pharmacoepidemiology and Pharmacoeconomics, Department of Medicine, Brigham and Women's Hospital and Harvard Medical \\ School, Boston, MA, USA.
}

BACKGROUND: New trial evidence suggests that many patients may require more aggressive pharmacologic management to achieve lower blood pressure goals. Especially when first initiating anti-hypertensive treatment, it is unknown whether starting patients on multiple medications may be better for long-term adherence and persistence compared with starting one medication.

OBJECTIVE: To examine contemporary patterns of antihypertensive therapy initiation and compare long-term adherence and persistence among patients initiating fixed-dose combinations and single anti-hypertensive therapies.

DESIGN: Retrospective cohort study.

PATIENTS: Using claims from a large nationwide insurer, we identified all patients initiating oral hypertension treatment from 2009 to 2013 . We categorized patients into three categories based on the number and type of anti-hypertensive medications they initiated: a fixeddose combination, a multi-pill combination or a single therapy.

MAIN MEASURES: The primary outcome was persistence to any anti-hypertensive medication, either the initiated medication or other anti-hypertensive, 12 months after initiation in administrative claims. We also measured adherence to at least one anti-hypertensive in the 12 months after initiation and refilling at least one anti-hypertensive medication as outcomes. Full adherence was defined as having $\geq 80 \%$ of potential days covered with medication. Multivariable modified Poisson regression models were used to examine the association between initiating a fixed-dose combination anti-hypertensive and medication outcomes.

KEY RESULTS: Of the 484,493 patients who initiated oral anti-hypertensives, 78,958 patients initiated fixeddose combinations, 383,269 initiated a single therapy, and 22,266 initiated multi-pill combinations. Patients initiating fixed-dose combinations were 9\% more likely to be persistent (relative risk [RR]: 1.09 , 95\% CI: $1.08-$ 1.10) and 13\% more likely to be adherent (RR: $1.1395 \%$ CI: 1.11-1.14) than those who started on a single antihypertensive therapy. Refill rates were also slightly higher among fixed-dose combination initiators.

CONCLUSIONS: Fixed-dose combination pills appear to enhance adherence and persistence to anti-hypertensive

Electronic supplementary material The online version of this article (doi:10.1007/s11606-016-3972-z) contains supplementary material, which is available to authorized users.

Received August 23, 2016

Revised November 21, 2016

Accepted December 15, 2016

Published online January 3, 2017 medications among commercially insured patients starting treatment compared with single therapy.

KEY WORDS: medication adherence; cardiovascular diseases; medication persistence; hypertension.

J Gen Intern Med 32(6):619-25

DOI: $10.1007 / \mathrm{s} 11606-016-3972-z$

(C) Society of General Internal Medicine 2016

\section{INTRODUCTION}

Of the more than 78 million adults in the United States with hypertension, only about half have their condition controlled based on current targets. ${ }^{1}$ Recent information from the landmark Systolic Blood Pressure Intervention Trial (SPRINT) suggests that some patients' blood pressure targets could be even lower than recommended by current guidelines in order to prevent complications. ${ }^{2}$ Many patients will require more aggressive pharmacologic management to achieve these targets; ${ }^{3,4}$ in SPRINT, the patients with a lower blood pressure target required on average one additional medication (2.7 vs. $1.8)^{2}$

There is clinical uncertainty about the best way to help patients reach blood pressure goals, especially when first initiating anti-hypertensive treatment. ${ }^{2}$ Prior studies have shown that fewer than $50 \%$ of patients continue to take their medications just 12 months after initiation. ${ }^{5,6}$ The question of whether starting patients on multiple medications is better for long-term adherence and persistence compared with starting one medication has not been sufficiently addressed, and the need for multidrug therapy to reach blood pressure targets will need to be balanced against increased risk of side effects. ${ }^{7}$

While the reasons for poor adherence are varied, complicated regimens and a larger number of medications can both reduce adherence. ${ }^{8} \mathrm{~A}$ few studies have found that fixed-dose combination (FDC) therapies (e.g., multiple medications in one pill) may be better for adherence than using two or more separate medications. ${ }^{9-11}$ Patients who report side effects are also much less likely to take medications as prescribed, and side effects increase with medication burden. ${ }^{8}$ Considering these potentially conflicting factors, little is known about whether adherence and persistence to therapy differs between patients who initiate a fixed-dose combination and those who begin monotherapy. Determining this relationship may inform the increasingly common clinical situation in which patients 
are initiating treatment for hypertension with the anticipation that multiple therapies will eventually be needed.

The goal of this study was to examine contemporary patterns of anti-hypertensive therapy initiation and compare persistence and long-term adherence to treatments among patients initiating fixed-dose combinations and other anti-hypertensive therapies. The second goal was to identify the demographic and clinical risk factors associated with selection of and adherence and persistence to anti-hypertensives.

\section{METHODS}

\section{Data Source and Patient Population}

We used administrative claims during 2009 to 2013 from a large national health insurer. These Health Insurance Portability and Accountability Act (HIPAA)-limited data include patient-level claims for medical inpatient and outpatient care: hospitalizations, procedures, office visits, emergency room visits, and outpatient pharmacy prescription drug claims. The data are also linked with patient enrollment data that include age and gender using a scrambled patient identifier. The Institutional Review Board of Brigham and Women's Hospital approved this study.

Our study population consisted of patients who initiated an oral anti-hypertensive medication between January 1, 2009, and December 31, 2012; the date of initiation is hereafter referred to as the "index date". To be included, patients had to be $\geq 18$ years of age and be continuously enrolled for $\geq 180$ days before and 365 days after their index date. Patients were excluded if they had previously filled any antihypertensive medication at any time prior to the index date. We chose initiation of an anti-hypertensive medication as our inclusion criteria, because receipt of an chronic medication may be considered a better indicator of a condition than diagnosis codes. ${ }^{12}$ Of the available oral anti-hypertensives, we also excluded sotalol, furosemide, and bumetanide, because they are often used for indications other than hypertension. The study selection criteria are shown in Online Appendix Table 1. The list of study medications is shown in Online Appendix Table 2.

\section{Utilization of Anti-Hypertensives}

We defined three drug combination categories classified by the number and type of medication initiated:

- Fixed-dose combination: A single pill containing multiple medications

- Multi-pill combination: Two or more distinct antihypertensive tablets or capsules filled on the index date

- Single therapy: Only one medication filled on the index date

These combinations were identified based on National Drug Codes (NDCs) and generic medication names at the time of dispensing on the index date. In the rare instance that patients initiated both fixed-dose combinations and other categories on the index date (e.g., filled both a fixed-dose combination and a single therapy; $<1 \%$ of patients), they were excluded from the overall cohort.

\section{Anti-Hypertensive Adherence and Persistence}

The primary outcome of interest was persistence to at least one anti-hypertensive medication 12 months after initiation. The secondary outcomes of interest were 1) adherence to at least one anti-hypertensive in the 12 months after initiation and 2) refilling at least one anti-hypertensive medication. To generate these outcomes, we created a drug supply diary by linking all observed fills after medication initiation based on dispensing date and days' supply. The supply for overlapping fills could accumulate up to 180 days of excess supply. Different drugs in the same chemically related therapeutic class (e.g., beta-blockers) were considered to be interchangeable. Mail order fills were included.

From these supply diaries, we defined persistence, or continuing treatment, as having supply for any anti-hypertensive that overlapped with the 365th day after initiation, whether the initiated medication or another anti-hypertensive; gaps at other times in the supply diary were allowed. ${ }^{13,14}$ This measure captures whether patients continued anti-hypertensive treatment. For the adherence measure, we calculated the proportion of days that patients had any anti-hypertensive available to them on that day, or the proportion of days covered (PDC), by dividing the number of days in which they had medication available by the number of follow-up days (e.g., 365 days). ${ }^{15}$ We defined patients as fully adherent if they were adherent (PDC $\geq 0.80$ ) to at least one anti-hypertensive in the 12 months after initiation, conforming to the level of medication adherence believed to be necessary to achieve clinically important effects. ${ }^{16,17}$ Because adverse events from an anti-hypertensive most frequently occur soon after the patient's first medication fill, we also examined whether patients returned for at least one refill in the 12 months after initiation as a proxy measure of early stopping of the new medications.

\section{Baseline Characteristics}

We measured baseline patient characteristics before antihypertensive initiation. Demographic characteristics such as age, region, and gender were obtained from the enrollment files at the time of therapy initiation. Clinical characteristics were measured in the 180 days prior to initiation using the International Classification of Diseases ninth edition (ICD-9) codes, including coronary artery disease, chronic obstructive pulmonary disease/asthma, hypertension, congestive heart failure (CHF), stroke, major depression, diabetes, liver disease, chronic kidney disease, Alzheimer's/dementia, and peripheral vascular disease. Patient utilization characteristics such as the number of unique prescriptions filled (by generic name), number 
Table 1 Patterns of Anti-Hypertensive Therapy Initiation in the Study Cohort

\begin{tabular}{|c|c|c|c|c|}
\hline Characteristic, $N(\%)$ & $\begin{array}{l}\text { Fixed-dose combination } \\
\text { (78,958 patients) }\end{array}$ & $\begin{array}{l}\text { Single therapy } \\
(383,269 \text { patients })\end{array}$ & $\begin{array}{l}\text { Absolute standardized } \\
\text { difference* }\end{array}$ & $\begin{array}{l}\text { Multi-pill combination } \\
\text { (22,266 patients) }\end{array}$ \\
\hline \multicolumn{5}{|l|}{ Demographic } \\
\hline Age, mean (SD) & $49.3(10.6)$ & $46.8(12.7)$ & 0.02 & $52.5(11.4)$ \\
\hline Female gender & $41,016(52.0)$ & $198,299(51.7)$ & 0.01 & 8107 (36.4) \\
\hline \multicolumn{5}{|l|}{ Region } \\
\hline West & $9476(12.0)$ & $61,426(16.0)$ & 0.16 & $3484(15.7)$ \\
\hline South & $46,176(58.5)$ & $193,935(50.6)$ & 0.18 & $10,971(49.3)$ \\
\hline Midwest & $18,499(23.4)$ & $93,293(24.3)$ & 0.03 & $6031(27.1)$ \\
\hline Northeast & $4807(6.1)$ & $34,615(9.0)$ & 0.16 & $1780(8.0)$ \\
\hline \multicolumn{5}{|l|}{ Clinical } \\
\hline Alzheimer's/Dementia & $146(0.2)$ & $1591(0.4)$ & 0.06 & $277(1.2)$ \\
\hline Congestive heart failure & $34(0.1)$ & $592(0.2)$ & 0.04 & $1651(7.4)$ \\
\hline Coronary artery disease & $108(0.1)$ & $5808(1.5)$ & 0.62 & $4514(20.3)$ \\
\hline COPD/Asthma & $1828(2.3)$ & $10,363(2.7)$ & 0.04 & $1260(5.7)$ \\
\hline Depression & $3631(4.6)$ & $24,235(6.3)$ & 0.11 & 1039 (4.7) \\
\hline Diabetes & $7271(9.2)$ & $44,318(11.6)$ & 0.11 & $3658(16.4)$ \\
\hline Kidney disease & $374(0.5)$ & $3168(0.8)$ & 0.06 & $792(3.6)$ \\
\hline Liver disease & $685(0.9)$ & $4922(1.3)$ & 0.06 & $812(3.7)$ \\
\hline Peripheral vascular disease & $116(0.2)$ & $1203(0.3)$ & 0.03 & $300(1.4)$ \\
\hline Stroke/TIA & $110(0.1)$ & $1484(0.4)$ & 0.13 & $550(2.5)$ \\
\hline \multicolumn{5}{|l|}{ Health utilization } \\
\hline Days hospitalized, mean (SD) & $0.2(1.8)$ & $0.7(4.7)$ & 0.03 & $3.6(9.9)$ \\
\hline No. unique drugs, mean (SD) & $4.0(3.0)$ & $4.8(3.6)$ & 0.07 & $5.9(3.5)$ \\
\hline No. outpatient visits, mean (SD) & $3.4(3.9)$ & $4.8(7.6)$ & 0.03 & $8.3(14.9)$ \\
\hline $\begin{array}{l}\text { Combined comorbidity score, } \\
\text { mean (SD) }\end{array}$ & $-0.6(0.9)$ & $-0.1(1.3)$ & 0.31 & $0.7(2.0)$ \\
\hline $\begin{array}{l}\text { Generic anti-hypertensive pre- } \\
\text { scription }\end{array}$ & $65,265(82.7)$ & $364,478(95.1)$ & 0.41 & $22,020(98.9)$ \\
\hline $\begin{array}{l}\text { Prescription copay }(\$) \text {, mean } \\
\text { (SD) }\end{array}$ & $14.4(19.7)$ & $9.6(11.2)$ & 0.02 & $18.3(18.0)$ \\
\hline Median (IQR) & $10.0(4.0-15.0)$ & $10.0(4.0-10.0)$ & & $15.0(8.0-18.0)$ \\
\hline No. index fills, mean (SD) & $1.0(0.0)$ & $1.0(0.0)$ & 0.00 & $2.2(0.5)$ \\
\hline Discharged within last 7 days & $604(0.8)$ & $20,761(5.4)$ & 0.70 & $8693(38.5)$ \\
\hline Discharged within last 30 days & $1019(1.3)$ & $24,823(6.5)$ & 0.70 & $9082(40.2)$ \\
\hline $\begin{array}{l}\text { Prescription days supplied for } \\
\text { anti-hypertensive } \leq 30\end{array}$ & $71,034(90.0)$ & $327,456(91.9)$ & 0.07 & $19,951(89.6)$ \\
\hline
\end{tabular}

Abbreviations: SD standard deviation, COPD chronic obstructive pulmonary disease, TIA transient ischemic attack, IQR interquartile range

*Comparing fixed-dose combinations with single therapies

of outpatient office visits, number of days hospitalized, and the combined comorbidity score ${ }^{18}$ were also measured in the 180-day period prior to initiation. Characteristics of the initiated anti-hypertensives were also measured, including the patient's copayment and number of days supplied on the initial prescription.

\section{Statistical Analysis}

The distribution of baseline characteristics among patients initiating antihypertensive medications was described. Absolute standardized differences, indexes that measure the effect size between groups to assess imbalance, were also provided to illustrate any differences between groups; a significant difference is usually characterized by an absolute standardized difference $>0.10$ (approximately equivalent to $p<0.05){ }^{19}$

First, each characteristic was tested separately to estimate its association with initiation of fixed-dose combinations and single therapies without controlling for other covariates, using modified Poisson regression models. These models generate the estimated relative risks (RRs) with robust standard errors, and are considered to be particularly appropriate when outcomes are common (e.g., incidences of $\geq 10 \%$ ). ${ }^{20}$ Next, multivariable modified Poisson regression models were used to examine the independent associations between patient characteristics and anti-hypertensive initiation.

Second, for each medication adherence and persistence outcome, we modeled the association between medication combination and outcome in an unadjusted analysis without controlling for other covariates, using modified Poisson regression models. We then modeled the association using multivariable models that adjusted for all measured patient baseline characteristics and examined the independent factors associated with adherence and persistence. Statistical significance was determined using two-sided tests with alpha $=0.05$. All analyses were conducted using SAS version 9.4 software (SAS Institute Inc., Cary, NC).

We also conducted a number of sensitivity analyses. First, we stratified the factors for adherence and persistence based on whether patients initiated fixed-dose combinations or single therapies. Second, we stratified the analyses by the index prescription's days supplied and also considered whether the results differed when "triamterene/hydrochlorothiazide" was considered a "single therapy" rather than a fixed-dose combination, because triamterene is almost never prescribed as a single therapy. Finally, we examined the number of unique anti-hypertensives and copayments in the 12 months after initiation to explore potential switches and augmentations. 


\section{RESULTS}

Our study sample consisted of 484,493 patients who initiated oral anti-hypertensives, including 78,958 patients initiating fixed-dose combinations, 383,269 who filled a single therapy, and 22,266 who initiated multi-pill combinations. The frequency of initiated medications across the three categories is shown in Online Appendix Tables 2 and 3. The most frequently initiated fixed-dose combination was lisinopril/ hydrochlorothiazide (38.4\%). Lisinopril (26.5\%), hydrochlorothiazide $(12.3 \%)$, and amlodipine $(13.3 \%)$ were the most frequently initiated single therapies. Patients' baseline characteristics are shown in Table 1 . The mean age was 47.2 years, and $51.8 \%$ were women; $46.9 \%$ had a diagnosis of hypertension in the prior 180 days, although chronic conditions are known to be poorly coded in claims. ${ }^{12}$

Patients initiating multi-pill combinations were much older and sicker and had more comorbidities than initiators of either a fixed-dose combination or single therapy. These patients were also much more likely to have been recently discharged from the hospital, and initiated different anti-hypertensives (Online Appendix Tables 2 and 3) than the other two groups. Consequently, we focused the main study comparisons on

Table 2 Factors Associated with Initiating a Fixed-Dose Combination Versus a Single Therapy

\begin{tabular}{|c|c|c|}
\hline $\begin{array}{l}\text { Characteristic (ref: } \\
\text { single therapy) }\end{array}$ & $\begin{array}{l}\text { Unadjusted RR } \\
(95 \% \mathrm{CI})\end{array}$ & $\begin{array}{l}\text { Adjusted RR* } \\
(95 \% \text { CI) }\end{array}$ \\
\hline \multicolumn{3}{|l|}{ Demographic } \\
\hline \multicolumn{3}{|l|}{ Age (ref: $<45$ years) } \\
\hline $45-54$ years & $1.44(1.42-1.47)$ & $1.33(1.31-1.35)$ \\
\hline$\geq 55$ years & $1.36(1.34-1.38)$ & $1.31(1.29-1.33)$ \\
\hline Female (ref: no) & $1.02(1.00-1.03)$ & $1.18(1.16-1.19)$ \\
\hline \multicolumn{3}{|l|}{ Region (ref: West) } \\
\hline South & $0.92(0.89-0.95)$ & $1.36(1.33-1.38)$ \\
\hline Midwest & $1.45(1.42-1.48)$ & $1.24(1.21-1.27)$ \\
\hline Northeast & $1.24(1.21-1.27)$ & $0.89(0.86-0.91)$ \\
\hline \multicolumn{3}{|l|}{ Clinical (ref: no) } \\
\hline Alzheimer's/ & $0.47(0.40-0.55)$ & $0.72(0.61-0.84)$ \\
\hline \multicolumn{3}{|l|}{ Dementia } \\
\hline Congestive heart & $0.16(0.10-0.26)$ & $0.52(0.32-0.84)$ \\
\hline failure & & \\
\hline Coronary artery & $0.08(0.07-0.10)$ & $0.17(0.14-0.22)$ \\
\hline \multicolumn{3}{|l|}{ disease } \\
\hline COPD/Asthma & $0.88(0.84-0.92)$ & $1.12(1.07-1.17)$ \\
\hline Depression & $0.76(0.73-0.78)$ & $0.91(0.89-0.94)$ \\
\hline Diabetes & $0.79(0.77-0.81)$ & $0.82(0.80-0.84)$ \\
\hline Kidney disease & $0.58(0.52-0.64)$ & $0.86(0.78-0.94)$ \\
\hline Liver disease & $0.71(0.66-0.77)$ & $1.08(1.01-1.16)$ \\
\hline Peripheral vascular & $0.48(0.39-0.57)$ & $0.72(0.60-0.86)$ \\
\hline \multicolumn{3}{|l|}{ disease } \\
\hline Stroke/TIA & $0.32(0.26-0.39)$ & $0.69(0.56-0.85)$ \\
\hline \multicolumn{3}{|l|}{ Health utilization } \\
\hline Hospitalized (ref: no) & $0.39(0.37-0.41)$ & $0.63(0.61-0.66)$ \\
\hline \multicolumn{3}{|c|}{ No. unique drugs (ref: 1) } \\
\hline 2 & $0.86(0.84-0.88)$ & $0.92(0.90-0.94)$ \\
\hline$\geq 3$ & $0.66(0.65-0.67)$ & $0.82(0.81-0.84)$ \\
\hline$\geq 2$ outpatient & $0.72(0.71-0.74)$ & $0.79(0.78-0.80)$ \\
\hline \\
\hline Comorbidity & $0.55(0.54-0.56)$ & $0.63(0.62-0.64)$ \\
\hline score: $\geq 1$ (ref: $\leq 0)$ & & \\
\hline \multicolumn{3}{|c|}{ Prescription copay (ref: $<\$ 10.00$ ) } \\
\hline$\geq \$ 10.00$ & $1.15(1.14-1.17)$ & $1.03(1.01-1.05)$ \\
\hline
\end{tabular}

Abbreviations: $R R$ relative risk, $C I$ confidence interval, COPD chronic obstructive pulmonary disease, TIA transient ischemic attack

*Includes all characteristics listed here patients initiating fixed-dose combinations and single therapies, because these groups were much more comparable in terms of baseline characteristics and medications initiated. By comparing these two groups, the analysis also removed the potential effect of a more complicated dosing regimen by exclusively examining patients using one anti-hypertensive pill.

As shown in Table 2, patients initiating a fixed-dose combination were more likely to be older and female. Fixed-dose combination initiators were also more likely to have COPD/asthma or concomitant liver disease, while other comorbidities (e.g., coronary artery disease or congestive heart failure) were more common in patients initiating a single therapy. Patients initiating a fixed-dose combination had slightly higher prescription copayments than patients using a single medication, but patients initiating single therapies had higher baseline healthcare resource utilization, including a recent hospitalization. These patient differences persisted after multivariable adjustment.

Patients initiating fixed-dose combinations had higher rates of persistence, adherence, and refilling anti-hypertensive medications in the year after initiating treatment compared with those initiating single therapies (Fig. 1). A total of 51.2\% of patients initiating fixed-dose combinations were persistent with any anti-hypertensive therapy 12 months after initiation, compared with $43.0 \%$ of patients initiating a single drug. Patients who initiated fixed-dose combinations also had higher rates of adherence than those initiating a single drug $(51.3 \%$ vs. $42.1 \%$ ). After multivariable adjustment, patients initiating fixed-dose combinations were $9 \%$ more likely to be persistent with anti-hypertensive treatment (relative risk [RR]: 1.09, 95\% CI: 1.08-1.10) and 13\% more likely to be adherent (RR: 1.13 95\% CI: 1.11-1.14) than patients initiating single-drug therapy (Table 3 ). Refill rates were also slightly higher among fixed-dose combination initiators.

The results from the multivariable regression analyses are shown in Table 4, providing estimates of the associations between patient characteristics and persistence and adherence to fixed-dose combinations, compared with single drug therapies. Increased age, dementia, congestive heart failure, coronary artery disease, COPD/asthma, diabetes, kidney disease, liver disease, and previous stroke were all associated with

Table 3 Association Between New Initiation of Fixed-Dose Combination and Single Therapy Anti-Hypertensives and Adherence

\begin{tabular}{|c|c|c|}
\hline \multirow[b]{2}{*}{ Measure } & \multicolumn{2}{|c|}{$\begin{array}{l}\text { Fixed-dose combination vs. Single anti- } \\
\text { hypertensive }\end{array}$} \\
\hline & $\begin{array}{l}\text { Unadjusted RR } \\
(95 \% \mathrm{CI})\end{array}$ & $\begin{array}{l}\text { Adjusted RR } \\
\text { (95\% CI) }\end{array}$ \\
\hline $\begin{array}{l}\text { Persistent to } \geq 1 \\
\text { antihypertensive }\end{array}$ & $1.19(1.18-1.20)$ & $1.09(1.08-1.10)$ \\
\hline $\begin{array}{l}\text { Adherent to } \geq 1 \\
\text { medication }\end{array}$ & $1.22(1.21-1.23)$ & $1.13(1.11-1.14)$ \\
\hline $\begin{array}{l}\text { Refilled } \geq 1 \\
\text { antihypertensive }\end{array}$ & $1.10(1.09-1.10)$ & $1.06(1.05-1.07)$ \\
\hline
\end{tabular}

Abbreviations: $R R$ relative risk, $C I$ confidence interval 


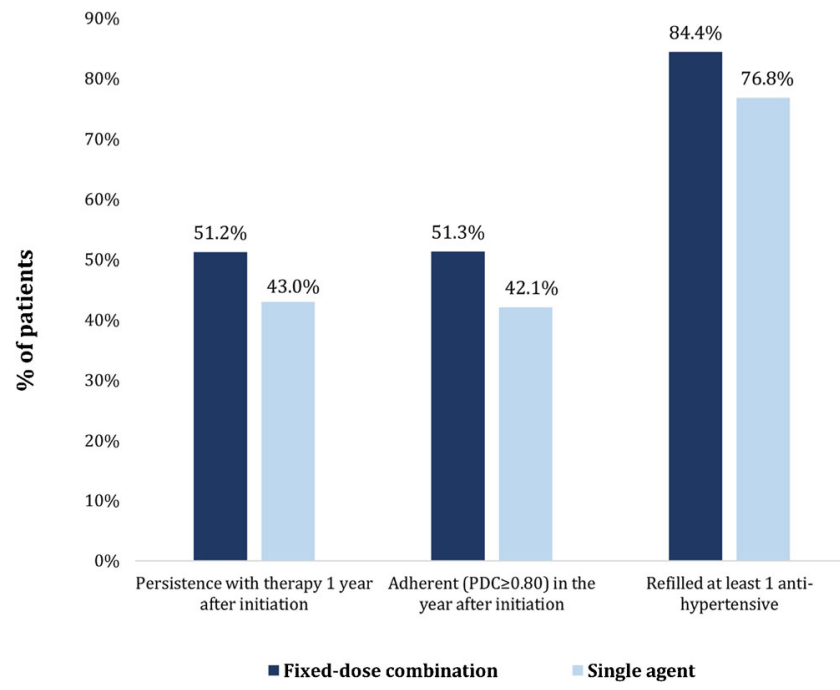

Fig. 1 Adherence and persistence to anti-hypertensive medications.

persistence and adherence in patients initiating fixed-dose combinations compared with single therapies. By contrast, women and those with a previous hospitalization were less likely to be adherent and persistent.

The results of our main sensitivity analyses are presented in Online Appendix Tables 4 and 5. These sensitivity analyses did not materially change the results. We also present the baseline patient factors associated with initiating fixed-dose and multi-pill combinations in Online Appendix Table 6. Comparisons between patients initiating fixed-dose and multi-pill combinations and adherence and persistence are shown in Online Appendix Table 7. Patients initiating fixeddose combinations were slightly less likely to be adherent and persistent than patients initiating multi-pill combinations.

Patients initiating fixed-dose combinations also filled fewer unique anti-hypertensive therapies in the 12 months after initiation (Online Appendix Figure 1) and remained on the same anti-hypertensive therapy (37.1\% vs. $33.5 \%$, or $25.5 \%$ of patients initiating single therapies or multi-pill combinations). Most patients who were persistent to fixed-dose combinations continued to use the same fixed-dose combination (59.4\%); $15.5 \%$ ended up on multiple medications (Online Appendix Table 8). Finally, we examined patients' copayments in the year after initiation, stratified by persistence (Online Appendix Table 9); copayments appeared to be similar.

\section{DISCUSSION}

Among a large nationwide sample of patients, we evaluated whether the initiation of multiple medications in a fixed-dose combination influenced adherence and persistence to antihypertensives compared with initiating a single therapy. We found that patients initiating fixed-dose combinations were 9\% more likely to be persistent and $13 \%$ more likely to be fully adherent in the 12 months after initiation than those started on a single anti-hypertensive therapy. We also found that patients initiating single therapies or multiple separate anti-hypertensives were sicker and more likely to have high resource utilization than patients initiating fixed-dose combinations.

Previous research has indicated that fixed-dose combinations can improve adherence compared with multi-pill combinations of the same medications. ${ }^{9-11}$ In one meta-analysis, fixed-dose combinations increased adherence compared with taking two separate individual medications (odds ratio [OR]: $1.21,95 \%$ CI: $1.03-1.43$ ) but did not differ in persistence (OR: $1.54,95 \%$ CI: $0.95-2.49$ ). ${ }^{10}$ However, these studies did not control for differences in regimen complexity or the effect of taking multiple medications. By contrast, in the present study, we examined whether adherence and persistence differed between patients who were taking only a single pill-comparing a fixed-dose combination pill versus a single agent pill.

Fixed-dose combinations have been increasingly recommended in clinical guidelines in order to enhance adherence to chronic medications by reducing pill burden and improving medication synchronization. ${ }^{21}$ The Food and Drug Administration (FDA) has even recently proposed that fixed-dose combinations could be eligible for a longer period of market exclusivity. ${ }^{22}$ Conversely, others have argued that fixed-dose combinations could limit dosing flexibility, particularly early after treatment initiation, when dose titrations may be needed, potentially leading to additional prescriptions intended to augment or replace the initial therapy, which could cause confusion about drug regimens. ${ }^{23}$ In addition, the fixed-dose combinations available do not always coincide with the therapies that a physician might select. ${ }^{24}$ In the present study, we observed no evidence that using fixed-dose combinations at antihypertensive initiation led to lower adherence or persistence compared with single therapies. In fact, we observed slightly better adherence and persistence among these patients and less medication switching after initiation. This finding is consistent with previous literature that suggests that anti-hypertensive combinations at lower doses can reduce the risk of adverse events compared with higher doses of one medication. ${ }^{25}$

Some observed differences in baseline characteristics between patients initiating and adhering to the different antihypertensive combinations have noteworthy implications for patient care. First, while prescription copayments were slightly higher for patients initiating fixed-dose combinations than those with single therapies, these increases did not appear to impact adherence or persistence. Second, older patients were more likely to initiate fixed-dose combinations and to be adherent and persistent in the year after starting therapy. Third, patients initiating multiple separate anti-hypertensive medications were much sicker than the other patient groups, and they initiated very different anti-hypertensives, making direct comparisons difficult. Finally, while women were more likely than men to initiate fixed-dose combinations, they were also less likely to remain adherent and persistent, which corroborates previous findings in other contexts. ${ }^{26}$ 
Table 4 Independent Factors for Adherence and Persistence Among Patients Initiating Fixed-Dose Combination And Single AntiHypertensives

\begin{tabular}{|c|c|c|c|c|}
\hline $\begin{array}{l}\text { Characteristic (ref: } \\
\text { single therapy) }\end{array}$ & $\begin{array}{l}\text { Persistence: Unadjusted } \\
\text { RR (95\% CI) }\end{array}$ & $\begin{array}{l}\text { Persistence: Adjusted RR } \\
\text { (95\% CI) }\end{array}$ & $\begin{array}{l}\text { Adherence: Unadjusted } \\
\text { RR (95\% CI) }\end{array}$ & $\begin{array}{l}\text { Adherence: Adjusted RR } \\
\text { (95\% CI) }\end{array}$ \\
\hline \multicolumn{5}{|l|}{ Demographic } \\
\hline \multicolumn{5}{|l|}{ Age (ref: $<45$ years) } \\
\hline $45-54$ years & $1.55(1.54-1.57)$ & $1.45(1.44-1.46)$ & $1.50(1.49-1.51)$ & $1.39(1.38-1.41)$ \\
\hline$\geq 55$ years & $1.77(1.75-1.79)$ & $1.63(1.62-1.65)$ & $1.69(1.67-1.70)$ & $1.54(1.53-1.56)$ \\
\hline Female (ref: no) & $0.83(0.82-0.84)$ & $0.91(0.90-0.92)$ & $0.82(0.81-0.83)$ & $0.89(0.88-0.90)$ \\
\hline \multicolumn{5}{|l|}{ Region (ref: West) } \\
\hline South & $1.01(1.00-1.02)$ & $1.00(0.99-1.00)$ & $1.00(0.99-1.01)$ & $0.98(0.97-0.99)$ \\
\hline Midwest & $1.14(1.13-1.16)$ & $1.12(1.11-1.14)$ & $1.13(1.12-1.14)$ & $1.11(1.10-1.13)$ \\
\hline Northeast & $1.09(1.07-1.10)$ & $1.08(1.06-1.09)$ & $1.09(1.08-1.11)$ & $1.08(1.06-1.09)$ \\
\hline \multicolumn{5}{|l|}{ Clinical (ref: no) } \\
\hline Alzheimer's/Dementia & $1.06(1.01-1.11)$ & $1.07(1.02-1.13)$ & $1.02(0.97-1.08)$ & $1.06(1.01-1.13)$ \\
\hline Congestive heart & $1.33(1.25-1.42)$ & $1.30(1.21-1.39)$ & $1.17(1.09-1.27)$ & $1.16(1.07-1.26)$ \\
\hline \multicolumn{5}{|l|}{ failure } \\
\hline Coronary artery disease & $1.36(1.33-1.39)$ & $1.52(1.48-1.56)$ & $1.42(1.39-1.45)$ & $1.71(1.67-1.76)$ \\
\hline COPD/Åsthma & $1.07(1.05-1.09)$ & $1.07(1.05-1.09)$ & $1.01(0.99-1.03)$ & $1.02(0.99-1.04)$ \\
\hline Depression & $0.89(0.87-0.90)$ & $0.98(0.97-0.99)$ & $0.88(0.87-0.90)$ & $0.98(0.97-1.00)$ \\
\hline Diabetes & $1.17(1.16-1.18)$ & $1.09(1.08-1.10)$ & $1.19(1.18-1.20)$ & $1.11(1.09-1.12)$ \\
\hline Kidney disease & $1.15(1.11-1.19)$ & $1.19(1.16-1.24)$ & $1.09(1.05-1.13)$ & $1.13(1.09-1.17)$ \\
\hline Liver disease & $1.05(1.02-1.08)$ & $1.20(1.17-1.23)$ & $1.02(0.99-1.05)$ & $1.17(1.13-1.20)$ \\
\hline Peripheral vascular & $1.24(1.18-1.30)$ & $1.04(0.99-1.10)$ & $1.19(1.13-1.25)$ & $1.02(0.97-1.08)$ \\
\hline \multicolumn{5}{|l|}{ disease } \\
\hline Stroke/TIA & $1.36(1.30-1.41)$ & $1.45(1.38-1.51)$ & $1.29(1.24-1.35)$ & $1.47(1.40-1.55)$ \\
\hline \multicolumn{5}{|l|}{ Health utilization } \\
\hline Hospitalized (ref: no) & $0.82(0.81-0.84)$ & $0.80(0.79-0.81)$ & $0.79(0.78-0.81)$ & $0.75(0.74-0.76)$ \\
\hline \multicolumn{4}{|l|}{ No. unique drugs (ref: 1) } & \\
\hline 2 & $0.97(0.95-0.98)$ & $0.98(0.97-1.00)$ & $0.97(0.96-0.98)$ & $0.99(0.97-1.00)$ \\
\hline$\geq 3$ & $0.93(0.92-0.94)$ & $0.99(0.99-1.00)$ & $0.92(0.91-0.93)$ & $1.02(1.01-1.03)$ \\
\hline $\begin{array}{l}\geq 2 \text { outpatient visits } \\
\text { (ref: } \leq 1 \text { ) }\end{array}$ & $0.97(0.96-0.98)$ & $1.01(1.00-1.02)$ & $0.97(0.96-0.98)$ & $1.02(1.01-1.03)$ \\
\hline Comorbidity score: & $0.68(0.67-0.69)$ & $0.73(0.72-0.74)$ & $0.69(0.68-0.70)$ & $0.74(0.73-0.75)$ \\
\hline \multicolumn{5}{|l|}{$\geq 1 \quad($ ref: $\leq 0)$} \\
\hline \multicolumn{5}{|c|}{ Days supplied (ref: $\leq 30$ days) } \\
\hline$>30$ days & $1.36(1.35-1.37)$ & $1.21(1.19-1.22)$ & $1.42(1.41-1.43)$ & $1.27(1.25-1.28)$ \\
\hline \multicolumn{5}{|c|}{ Prescription copay (ref: $<\$ 10.00$ ) } \\
\hline$\geq \$ 10.00$ & $0.99(0.98-1.00)$ & $1.00(0.99-1.01)$ & $1.01(1.00-1.02)$ & $1.00(0.99-1.02)$ \\
\hline
\end{tabular}

Abbreviations: RR relative risk, CI confidence interval, COPD chronic obstructive pulmonary disease, TIA transient ischemic attack

Recent evidence from a trial conducted among patients $\geq 50$ years of age with elevated cardiovascular risk suggests that controlling hypertension to a blood pressure target lower than current guidelines will improve patient outcomes. ${ }^{2}$ While the patients in the present study were younger and had fewer comorbidities, clinicians may still try to treat patients to lower blood pressure levels, including aggressive combinations of anti-hypertensive treatments and lifestyle modifications. This study provides timely guidance for clinicians who may be considering whether to initiate multiple anti-hypertensives in a patient who is beginning treatment. These findings support the conclusion that patients initiating anti-hypertensive treatment could benefit from multiple medications contained in a fixed-dose combination pill rather than a single therapy.

Our study has several limitations. First, our data source includes only commercially insured patients or those with Medicare Advantage, and may not be representative of all patients in the United States. Second, we did not have detailed clinical information available about patients at the time of the clinical encounter or during follow-up, including blood pressure values or hypotension, because we were limited to administrative claims data; patients may have also initiated medications for indications other than hypertension. This study also did not assess clinical outcomes, which should be further examined in future studies. In addition, because the study is based on administrative data, some bias or confounding by indication is possible because of inadequately measured predictors, such as socioeconomic or other clinical variables, if they were differential between the groups. Given the nature of the data, medication adherence and persistence were measured indirectly using days' supply, a validated method that has been shown to correlate well with electronic records and patient self-report. ${ }^{27}$ Any discontinuation that occurs may also be clinically appropriate. These measures considered only whether patients were adherent or persistent to at least one medication, but mirror those used by health plans and the Centers for Medicare and Medicaid Services to assess quality of care. ${ }^{28}$

\section{CONCLUSION}

We found that patients initiating a single pill containing a fixed-dose combination of anti-hypertensive medications were more likely to be persistent and fully adherent than those initiating a single therapy, based on administrative claims in the 12 months after initiation. We also found that male gender, age, and concomitant cardiovascular conditions were some of the strongest factors associated with adherence and persistence 
to these combinations. For patients beginning antihypertensive treatment, clinicians may want to consider starting patients on a fixed-dose combination pill rather than a single therapy.

Acknowledgements: This was an unfunded study.

Corresponding Author: Julie C. Lauffenburger, PharmD, PhD; Division of Pharmacoepidemiology and Pharmacoeconomics, Department of MedicineBrigham and Women's Hospital and Harvard Medical School, 1620 Tremont Street, Suite 3030, Boston, MA 02120, USA (e-mail: jlauffenburger@bwh.harvard.edu).

\section{Compliance with Ethical Standards:}

Conflict of Interest: Dr. Lauffenburger has received unrestricted research funding payable to her institution from AstraZeneca. Dr. Fischer has received prior support through his institution from CVS Health and Otsuka America for research on medication adherence. All remaining authors declare that they do not have a conflict of interest.

\section{REFERENCES}

1. Gu Q, Burt VL, Dillon CF, Yoon S. Trends in antihypertensive medication use and blood pressure control among United States adults with hypertension: the National Health And Nutrition Examination Survey, 2001 to 2010. Circulation. 2012;126(17):2105-2114.

2. Group SR, Wright JT Jr, Williamson JD, et al. A Randomized Trial of Intensive versus Standard Blood-Pressure Control. N Engl J Med 2015;373(22):2103-2116.

3. Perkovic V, Rodgers A. Redefining Blood-Pressure Targets-SPRINT Starts the Marathon. N Engl J Med. 2015;373(22):2175-2178.

4. Drazen JM, Morrissey S, Campion EW, Jarcho JA. A SPRINT to the Finish. N Engl J Med. 2015;373(22):2174-2175.

5. Yeaw J, Benner JS, Walt JG, Sian S, Smith DB. Comparing adherence and persistence across 6 chronic medication classes. J Manag Care Pharm. 2009; 15(9):728-740.

6. Baroletti S, Dell'Orfano H. Medication adherence in cardiovascular disease. Circulation. 2010;121(12):1455-1458.

7. Gellad WF, Grenard JL, Marcum ZA. A systematic review of barriers to medication adherence in the elderly: looking beyond cost and regimen complexity. Am J Geriatr Pharmacother. 2011;9(1):11-23.

8. Osterberg L, Blaschke T. Adherence to medication. N Engl J Med. 2005;353(5):487-497.

9. Bangalore S, Kamalakkannan G, Parkar S, Messerli FH. Fixed-dose combinations improve medication compliance: a meta-analysis. Am J Med. 2007;120(8):713-719.

10. Gupta AK, Arshad S, Poulter NR. Compliance, safety, and effectiveness of fixed-dose combinations of antihypertensive agents: a meta-analysis. Hypertension. 2010;55(2):399-407.

11. Pan F, Chernew ME, Fendrick AM. Impact of fixed-dose combination drugs on adherence to prescription medications. J Gen Intern Med. 2008;23(5):611-614.
12. Miller DR, Safford MM, Pogach LM. Who has diabetes? Best estimates of diabetes prevalence in the Department of Veterans Affairs based on computerized patient data. Diabetes Care. 2004;27(Suppl 2):B10-B21.

13. Hiligsmann M, Boonen A, Rabenda V, Reginster JY. The importance of integrating medication adherence into pharmacoeconomic analyses: the example of osteoporosis. Expert Rev Pharmacoecon Outcomes Res. 2012;12(2):159-166.

14. Cramer JA, Roy A, Burrell A, et al. Medication compliance and persistence: terminology and definitions. Value Health. 2008;11(1):44-47.

15. Benner JS, Glynn RJ, Mogun H, Neumann PJ, Weinstein MC, Avorn J. Long-term persistence in use of statin therapy in elderly patients. JAMA. 2002;288(4):455-461.

16. Steiner JF, Koepsell TD, Fihn SD, Inui TS. A general method of compliance assessment using centralized pharmacy records. Description and validation. Med Care. 1988;26(8):814-823

17. Choudhry NK, Glynn RJ, Avorn J, et al. Untangling the relationship between medication adherence and post-myocardial infarction outcomes: medication adherence and clinical outcomes. Am Heart J. 2014;167(1):51-58. e55.

18. Gagne JJ, Glynn RJ, Avorn J, Levin R, Schneeweiss S. A combined comorbidity score predicted mortality in elderly patients better than existing scores. J Clin Epidemiol. 2011;64(7):749-759.

19. Austin PC. Balance diagnostics for comparing the distribution of baseline covariates between treatment groups in propensity-score matched samples. Stat Med. 2009;28(25):3083-3107.

20. McNutt LA, Wu C, Xue X, Hafner JP. Estimating the relative risk in cohort studies and clinical trials of common outcomes. Am J Epidemiol. 2003;157(10):940-943.

21. James PA, Oparil S, Carter BL, et al. 2014 evidence-based guideline for the management of high blood pressure in adults: report from the panel members appointed to the Eighth Joint National Committee (JNC 8). JAMA. 2014;311(5):507-520.

22. U.S. Department of Health and Human Services Food and Drug Administration. Guidance for industry: new chemical entity exclusivity determinations for certain fixed-combination drug. 2014. http://www. fda.gov/downloads/Drugs/GuidanceComplianceRegulatoryInformation/ Guidances/UCM386685.pdf (accessed December 13, 2016).

23. Gautam CS, Saha L. Fixed dose drug combinations (FDCs): rational or irrational: a view point. Br J Clin Pharmacol. 2008;65(5):795-796.

24. Wang B, Choudhry NK, Gagne JJ, Landon J, Kesselheim AS. Availability and utilization of cardiovascular fixed-dose combination drugs in the United States. Am Heart J. 2015;169(3):379-386. e371.

25. Law MR, Wald NJ, Morris JK, Jordan RE. Value of low dose combination treatment with blood pressure lowering drugs: analysis of 354 randomised trials. BMJ. 2003;326(7404): 1427.

26. Lauffenburger JC, Robinson JG, Oramasionwu C, Fang G. Racial/Ethnic and gender gaps in the use of and adherence to evidence-based preventive therapies among elderly Medicare Part D beneficiaries after acute myocardial infarction. Circulation. 2014;129(7):754-763.

27. Hansen RA, Kim MM, Song L, Tu W, Wu J, Murray MD. Comparison of methods to assess medication adherence and classify nonadherence. Ann Pharmacother. 2009;43(3):413-422.

28. Schmittdiel JA, Nichols GA, Dyer W, Steiner JF, Karter AJ, Raebel MA. Health care system-level factors associated with performance on Medicare STAR adherence metrics in a large, integrated delivery system. Med Care. 2015;53(4):332-337. 